\title{
Notas para uma pedagogia oswaldiana: filosofia e antropofagia
}

\author{
Marcelo Vieira Lopes ${ }^{1}$
}

\begin{abstract}
Resumo
O presente artigo pretende esboçar, em linhas gerais, uma prática filosófica no ensino médio que tente pensar a filosofia a partir da sua realidade irredutível, o contexto social brasileiro. A justificativa para tal abordagem parte da obra de Oswald de Andrade como precursor daquilo que no título denominamos uma prática filosófica antropofágica. Nossa abordagem tenta pensar $o$ ensino de filosofia no Brasil no que teríamos de mais característico a oferecer, isto é, não mais a mera reprodução dos cânones do pensamento ocidental, mas sim, uma apropriação legitimamente latino-americana, emancipatória e insurgente, na medida em que busca fornecer ao aluno um potencial para apropriar-se e desapropriar-se de tais conteúdos, na medida em que lhes aprouver. A proposta de pensar o ensino de filosofia por vias não tradicionais, está diretamente ligada à obra de Oswald de Andrade, em particular os dois Manifestos dos anos 20; a partir das ideias de uma Antropofagia, visamos elucidar a necessidade de um pensamento e uma prática filosófica não debitária e meramente reprodutiva do modo de pensar ocidental tradicional. Esse trabalho, além do esforço empregado para pensar contra a corrente é também algo de contraditório: ao mesmo tempo em que critica as normas e regras de escrita, se submete às mesmas; critica e subverte sem deixar os padrões, em suma, mantém-se amarrado pela própria forma de fazer filosofia no Brasil. Mas, desgostos e formalidades à parte, tentaremos colocá-lo, ainda que a contragosto, dentro dos padrões e do lugar do pensamento sobre o ensino de filosofia no Brasil.
\end{abstract}

Palavras-chave: Antropofagia; Ensino de Filosofia; Filosofia Brasileira.

\section{Apuntes para una pedagogía oswaldiana: filosofía e antropofagía}

\section{Resumen}

Este artículo pretende esbozar, en general, una práctica filosófica en la escuela secundaria para tratar de pensar la filosofía e su realidad irreductible, el contexto social brasileño. La justificación de este enfoque parte del labor de Oswald de Andrade como un precursor de lo que llamamos una práctica filosófica antropogágica. Como hemos dicho, este enfoque trata de pensar la enseñanza de la filosofía en Brasil en lo que tendríamos más característico que ofrecer, es decir, no la mera reproducción de los cánones del pensamiento occidental sino más bien una apropiación legítima latinoamericano, emancipadora e insurgente, mientras que trata de proporcionar al estudiante un potencial de apropiación y desalojarlo de tales contenidos, en la medida en que consideren oportuno. La propuesta de pensar la

\footnotetext{
${ }^{1}$ Mestrando em Filosofia pela Universidade federal de Santa Maria.

E-mail: nerofil@live.com
} 
enseñanza de la filosofía en formas no tradicionales, está directamente vinculado a la obra de Oswald de Andrade, en particular, los dos Manifiestos de los años veinte; Desde las ideas de una Antropofagia, nuestro objetivo es dilucidar la necesidad de un pensamiento y una práctica filosófica no meramente reproductiva y debitária a la manera occidental tradicional de pensar. Este trabajo, además del esfuerzo realizado para pensar corriente arriba también es algo contradictoria: mientras critica las normas y reglas de escritura, está sujeto a la misma; critica y subvierte sin abandonar las normas, en una palabra, queda atada el método de hacer filosofía en Brasil. Pero, disgustos y formalidades a un lado, tratamos de ponerlo, aunque de mala gana, dentro de las normas y lugar de pensar sobre enseñanza de la filosofía en Brasil.

Palabras clave: Antropofagia; Enseñanza de la filosofía; Filosofía brasileña.

\section{Introdução: pensando com o estômago²}

Diz-se da antropofagia como a prática ritual ou não de devorar carne humana. Diz-se também que dentre os povos em que a prática foi encontrada, na maioria das vezes, estava a ela vinculada a ideia de que ao assimilar a carne do devorado, o devorador viria, logo em seguida a adquirir os poderes do inimigo derrotado.

Fato é que durante séculos, essa foi uma prática senão comum, ao menos constante entre o gentio americano. O fenômeno da devoração humana, independente da abordagem que a ele se dê, manifesta algumas peculiaridades quanto ao modo de ser peculiar do americano, ou nesse caso, do ameríndio. Depois veio a descoberta, melhor dizendo, a invasão, o saque e a "catequese". Com os europeus, descobriu-se, inventou-se o sentido negativo da antropofagia. "Aqui havia gente, e gente que comia gente". Alguns séculos de saques e devoração (em sentido mercadológico), deixaram o Brasil, entendido naquele período como colônia, em "dívida" cultural e econômica com Portugal. A boa e

\footnotetext{
2 "Tobias Barreto advertia que o brasileiro não tem cabeça filosófica, mas talvez o brasileiro ( e o latino-americano) tenha outras partes do corpo que sejam filosóficas. Não se filosofa apenas com a cabeça, ou talvez o europeu filosofou apenas com a cabeça, mas nós utilizamos outras partes do corpo além dela. Talvez o nosso estômago seja mais filosófico que nossa cabeça. É com o estômago que Oswald pensa a superação de limites, a passagem do tabu ao totem, a genuína assimilação. E bom proveito" (CABRERA, 2010, p. 169).
} 
velha lógica da dominação entra em cena pela primeira vez em nossa história, logo após nossa "descoberta".

No que concerne especificamente à dívida cultural para com a metrópole é que irão rebelar-se alguns dos mais notáveis antropófagos brasileiros, no começo da década de vinte do século passado. Estes, embora não devorassem no sentido literal da palavra, tentaram à sua maneira pôr em prática a devoração de outrora. O movimento antropofágico, nascido do seio da civilização brasileira, em pleno desenvolvimento, reclamava agora os direitos daqueles outros antropófagos, os primeiros. Sob a tutela de Oswald de Andrade, nasce o movimento antropofágico, insurgente contra toda a literatura e cultura predominante no Brasil "catequizado".

A antropofagia aqui assinalada em termos de uma renovação e retomada da cultura autenticamente brasileira pretendia levar até as últimas consequências o retorno ao indígena, ao nativo, ao primitivo. Benedito Nunes classifica o que ele chama de "Visão poética Pau-Brasil" em termos de uma busca e retorno a uma espécie de primitivismo, buscando no pensamento selvagem a procura das fontes emotivas, donde jorram os estados brutos da alma coletiva, enquanto fatos culturais (NUNES, 1978, p. xix). Nesse sentido, o manifesto Pau-Brasil oferece, na visão de Benedito Nunes "um modo de sentir e conceber a realidade", bem como "o programa de uma reeducação da sensibilidade e uma teoria da cultura brasileira". (1978, p. xx).

O ideal educativo da antropofagia, em sentido amplo, se assim nos é permitido falar, seria o de conciliar a cultura nativa e toda a cultura intelectual renovada, "a floresta com a escola" (1978, p.xxiii), numa massa única e miscigenada que ratificaria a constituição étnica do povo brasileiro. Juntamente com os componentes "irracionais" e "inconscientes" de toda uma cultura, apareceriam também, na forma de novos valores a serem incorporados (ou velhos a serem resgatados): o ócio, a comunhão fraterna, a sociedade dadivosa, a liberdade sexual e a vida edênica." (1978, p. xix). Tais seriam, se formulados em termos dogmáticos, os prospectivos para uma educação Pau-Brasil. O ponto alto da análise de Benedito Nunes para aquilo que apropriativamente (talvez de modo 
indevido) chamamos aqui de "ideal educativo da antropofagia" é a reconstrução de uma "Metafísica bárbara", baseada no uso mesmo da noção de antropofagia como uma filosofia brasileira. Todas as sátiras e ataques de que se valem os manifestos estão carregados contra o modo de saber vigente até então: o europeu. Todo arcabouço conceitual ali desenvolvido, visa uma filosofia canibal, antropofágica, em seu pleno desenvolvimento: destrutiva e prospectiva. O que se visa com essa autêntica filosofia brasileira - se não for heresia assim chamá-la para os padrões acadêmicos - a antropofagia, é assim, antes de tudo, símbolo de devoração. Tal como uma metáfora da cerimônia guerreira da imolação tupi do inimigo, apresado em combate, engloba tudo aquilo que deveríamos repudiar, assimilar e superar para a conquista de nossa autonomia intelectual. (1978, p. xxv). Após essa breve reconstrução da filosofia antropofágica, ainda que parcial, é necessário trazermos a análise dos manifestos e mais alguns textos, dentre os quais, Benedito Nunes qualificou como os "escritos doutrinários" de Oswald de Andrade. São eles os dois manifestos, de 1924 e 1928, bem como alguns textos filosóficos (no sentido mais rigoroso da palavra), datados do início dos anos 50.

\section{Os Manifestos}

Dentre os escritos doutrinários de Oswald encontram-se os dois manifestos: o da Poesia Pau-Brasil e o Antropófago, donde pensamos o potencial pedagógico da antropofagia. "Bárbaro e nosso" (ANDRADE, 1970, p.05), diz o poeta. E é assim que gostaríamos de introduzir os manifestos como possibilidades de pensar o ensino de filosofia no Brasil. "A língua sem arcaísmos, sem erudição. Natural e neológica. A contribuição milionária de todos os erros. Como falamos, como somos."(1970, p.06). Esta passagem expressa grande parte do que entendemos como uma prática filosófica antropofágica. A língua falada, a língua vivida, errante, como somos na escola. Não entramos sabendo; Em suma, não sabemos nada, enquanto buscamos uma cultura alheia. A "contribuição milionária de todos os erros" está justamente aí, em sermos quem somos: tortos, errados e avessos à cultura ocidental, que engessa nossa natural plasticidade e movimento. 
Os manifestos trazem à tona a irreversível inconstância de nossa alma e a recusa de toda e qualquer doutrina, embora aparentemente nos atenhamos a elas por algum tempo: "contra a cópia, pela invenção e pela surpresa". (1970, p.06). É através dos manifestos que ganha forma uma maneira de pensar o ensino de filosofia no ensino médio, ainda que de forma bastante embrionária. A ênfase que notamos em Oswald, recai sempre sobre o aspecto criativo, emancipatório, insurgente de um pensamento legitimamente brasileiro: "Tupi or not Tupi that is the question." (1970, p.13). Dessa forma, o ensino de filosofia baseado nas ideias antropofágicas é mais criativo que repetitivo. Ele é inovador por si só. Não pretendemos ao trazer Oswald e os antropófagos para o debate, classificá-los como filósofos ou não. Isso está fora de questão. Nosso ponto é completamente outro: como pensar o ensino de filosofia a partir desses moldes antropofágicos?

No Manifesto antropofágico, a insurreição e a bandidagem do conceito são exaltadas. A sentença "Só a antropofagia nos une." (1970, p.13), pode muito bem ser interpretada em chave de insurgência. É o que temos em comum, quando o devorado e o devorador tornam-se um só. Filosofia e filosofante - unidos antropofagicamente. Obviamente essa linha de leitura violenta (contra todas as catequeses), que fazemos do texto oswaldiano, tentando pensá-lo a partir de nossos propósitos parece, em última instância, corroborar com uma tese que, conforme acreditamos, agradaria o próprio Oswald: "Só me interessa o que não é meu. Lei do homem. Lei do antropófago."(1970,p.13).

É justamente este não-ser-meu que permeia toda a atividade antropofágica o que mais chama a atenção como potencial pedagógico latente. A filosofia, de fato, nunca é nossa. Nunca nos apropriamos dela e a detemos. Ela sempre escapa. Para o aluno de ensino médio, ela nem sequer chegou. Os mecanismos de pensar a que está condicionado o adolescente (as catequeses) não permitem que este sequer se interesse pela disciplina. É nesse sentido em que falávamos de uma bandidagem conceitual. Aquilo que não é meu, que por tradição não é meu, deve em algum momento ser apropriado. Mas como?

\section{Oswald de Andrade educador}


O ponto central do presente trabalho seria então explicitar algumas relações que até então parecem operar como que nas entrelinhas, subjacentes às concepções antropofágicas e a ideia do ensino de filosofia no ensino médio. Tal trabalho desdobra-se então em uma série de questões, onde se encontram entrelaçados os conceitos de antropofagia, apropriação e autonomia. Como tais conceitos podem vir a configurar um modelo didático para o ensino de filosofia a nível médio é o desafio que aqui nos propomos. Nesse ponto, cabe perguntar: como o conceito de antropofagia, via noção de apropriação pode contribuir para o desenvolvimento da autonomia do aluno? Qual a ligação entre o conceito de antropofagia e o conceito de apropriação? Em que sentido Oswald de Andrade pode ser visto como educador? Em que medida a antropofagia pode ser tomada como "proposta pedagógica"? Qual a sua proposta pedagógica? Em suma, quais são os sentidos e limites da antropofagia enquanto potencial pedagógico?

\section{Devoração e apropriação como método}

A proposta de pensar o ensino de filosofia por vias não tradicionais, baseia-se como já exposto, na noção antropofágica, carregada com todos os sentidos que esta adquire a partir da Semana de Arte de 1922. Ela está diretamente ligada à necessidade de um pensamento não debitário e reprodutivo do pensar ocidental tradicional. Se, por um lado, buscamos cada vez mais incessantemente como ensinar filosofia, é através do conceito de Antropofagia de Oswald e do movimento modernista que buscaremos a chave para pensar um ensino de filosofia inserido, enraizado, tal como a Poesia Pau-brasil. Tal "pratica filosófica antropofágica" consiste na constante apropriação dos elementos da tradição ocidental, adaptados à fome do aluno, ou daqueles envolvidos na prática filosófica. A filosofia aqui assume um papel ritual de devoração, deglutição e assimilação conceitual, por parte do aluno, o "bom selvagem", ainda não catequizado, que segundo nossa concepção deve assim permanecer, arisco às armadilhas conceituais, ao pensamento pronto, ao pensamento de manual. "Contra todas as catequeses. [...] Só me interessa o que não é meu. Lei do homem. Lei do antropófago." (1970, p.13). Assim diz Oswald no início de seu Manifesto 
Antropófago, convocando-nos para uma verdadeira apropriação do selvagem antropófago que há em nós.

É através desta compreensão da antropofagia como potencial pedagógico que tentaremos pensar uma proposta emancipatória para o ensino de filosofia no ensino médio. Nesse horizonte surge o ensino de filosofia não apenas como uma mera reprodução de conteúdos herdados da tradição ocidental, mas como apropriação conceitual que surge da necessidade do aluno "não catequizado" a assimilar esses mesmos conteúdos à sua maneira, ou seja, como melhor the aprouver. Aqui, uma ressalva torna-se necessária. A partir da perspectiva antropofágica, posicionamo-nos de forma crítica às diretrizes gerais estabelecidas para o ensino médio, levando em conta a dimensão do trabalho sempre em primeiro plano quando se trata do ensino. A velha questão: formar "cidadãos críticos" (dentro dos parâmetros preestabelecidos) e "eticamente responsáveis". Pensamos que através dessa noção, a saber, o trabalho como o norte que guia toda a educação, exclui-se a possibilidade de qualquer forma autenticamente original de pensar, transgressora e insurgente, tal como concebemos a ideia da filosofia. É a partir da ideia do "ócio contra o negócio", nos moldes oswaldianos, que tentamos conceber como seria uma praxis filosófica verdadeiramente tupiniquim. Nessa visão, a filosofia não está subordinada ao negócio, visando como fim último uma recompensa profissional, financeira, mas sim, pensar o indivíduo inserido dentro de nossa cultura e nossa época histórica; em última instância, carente de um pensar autenticamente vinculado às suas raízes e seu dia a dia.

Aqui, o conceito de apropriação talvez devesse ser melhor articulado: a filosofia, como disciplina a ser trabalhada na escola, não deve, nem pode ser transmitida. Ao contrário, deve ser apropriada pelo aluno, isto é, frente aos diversos temas e conteúdos filosóficos, deve este apropriar-se à sua maneira de conceitos e definições herdados da tradição. Nesse sentido, concordamos completamente com Ceppas, quando este afirma:

É a cultura, em sentido amplo, que dá régua e compasso ao sentido que pode ter, na escola, uma experiência de pensamento propriamente filosófica", fazendo uma verdadeira ode ao antropófago esquecido que há em nós: "[...] a generosidade do tempo-ócio do selvagem contra a avareza do tempo-negócio do 
protestantismo anglo-saxão. A antropofagia não é mera metáfora devoradora da alegria cultural dos trópicos. Ela é o centro a partir do qual valores propriamente tupiniquins podem ter alguma ressonância e conflitar com os valores do Ocidente: 'havia aqui gente e gente que comia gente' (CEPPAS, 2013, p.3).

Cabe então ao professor de filosofia a tarefa de despertar a fome conceitual e apropriativa que deve reger as atividades filosóficas em sala de aula. O professor como Pajé: guia de um mundo desconhecido e estranho aos alunos. O aluno, no entanto, imerso na prática filosófica antropofágica não é mero espectador, como se espera de uma classe "normal". O que se espera do aluno dentro dessa perspectiva é justamente a insurgência, a inquietação e o movimento do pensamento. Tanto o aluno quanto o professor, vistos desde essa perspectiva são agentes de seu próprio ensino, de sua apropriação e autossuficiência filosófica. Outra maneira rica de pensarmos o ensino de filosofia no Brasil, ou a filosofia como tal, é pensarmos sempre em sua situação inalterável, seu lugar em um tempoespaço contínuo, condicionante - queiramos ou não - de todo ato de pensamento. Tal concepção implicaria primeiramente algumas considerações sobre o contexto histórico, político, social e por que não, metafísico em que estamos inseridos:

Pensar, indagar e indagar-se não são coisas que o humano faça por opção, mas algo ao qual ele é impulsionado pelo simples fato de ser. Este é o ambiente em que prefiro pensar a filosofia. Um lugar onde ela perde a insolente precisão da atual definição acadêmica (CABRERA, 2010, p.13. Grifo nosso).

Nesse sentido, Cabrera insere uma relação de igualdade entre o filosofar e a forma humana de ser - essencial para o modelo que pensamos a prática filosófica em sala de aula. Não desvinculamos a filosofia da vida do aluno, mas, ao contrário, procuramos mostrar que aquilo que o perturba em sua vida cotidiana, pode tornar-se (se já não é, em um sentido muito incipiente) justamente sua filosofia, sua vida, aquilo pelo que ele se interroga e é desde sempre uma questão para si. A ideia, portanto, de um filosofar desde o Brasil, tão cara a Cabrera, não está vinculada ao sentido geográfico e local, obviamente contingente, em que o aluno está inserido. 
Este desde ganha um sentido muito mais vital, na medida em que a inserção individual deste aluno em particular não poderia ser pensada a partir de outro lugar, ou "do ponto de vista de lugar nenhum", tal como pretende a forma tradicional de filosofar, universalizante do pensamento.

É justamente a partir dessas duas concepções, tanto a de Oswald, como a de Cabrera, que buscamos pensar um ensino de filosofia partindo desde o Brasil, ou desde e para o aluno, visto que o ensino tem (ou, pelo menos, deveria ter) o seu fim justamente neste último. Como tal, o ensino de filosofia tradicional perde o seu sentido, pois o fim buscado é sempre em termos de preparação para o mercado de trabalho, para o vestibular, em suma, para fins externos que o aluno mesmo. Sob as formas mascaradas de educação crítica, preparo tecnológico e acordo com princípios éticos, escondem-se basicamente a necessidade de produzir sujeitos cada vez mais aptos para um mercado de trabalho cada vez mais tecnicizado e competitivo. A filosofia estaria assim, em função do "negócio" ao invés do "ócio", portanto, não mais em função das necessidades intrínsecas, e por que não, existenciais do aluno. Nesse ponto, podemos inserir a metáfora do devorar, como imagem do que entendemos por uma pedagogia antropofágica:

\begin{abstract}
Num sentido literal, muitos europeus conquistadores foram capturados pelos índios e devorados. Os índios são, pois, os bárbaros, perigosos e nus, e o homem culto e vestido corre perigo entre eles. A reflexão oswaldiana tenta dar uma significação filosófica a esta relação brutal e aparentemente irresgatável, arriscando uma interpretação do comer europeus que faça sentido para a constituição da nossa cultura, para que o devorar não seja visto como bárbaro, mas como uma maneira própria de se relacionar com a cultura do estrangeiro sem ser devorado por ela (CABRERA, 2010, p.165).
\end{abstract}

É nessa direção que pensamos um ensino de filosofia apropriativo por excelência, em que o aluno relaciona-se direta e afetivamente com seu alimento filosófico. "Nós não especulamos, nós comemos!" (2010, p. 168). Pensar a filosofia e seu ensino nesses termos equivale a abrir mão do comodismo dos cânones ocidentais, centenários do aprender e do ensinar. O ensino assim concebido mostra-se como um gesto de comunhão ritual do alimento a ser devorado, seja um texto de Hegel ou o debate acerca da ética da libertação animal. Ambos são 
concebidos como um movimento de apropriação daquilo que não é seu, culturalmente, essencialmente, mas que por outro lado é incorporado através de algumas práticas (porque não rituais?), tais como a escola, os institutos de ensino, etc. A proposta de trabalho de pensar o espaço, o lugar e o tempo do pensamento no ensino médio como algo de diferente, de canibal, visa justamente desconstruir em última instância a escola como escola; a filosofia como filosofia. Em suma, o que fazemos aqui nos trópicos, se comparado aos cânones ocidentais do pensamento é tudo, menos filosofia: melhor para nós.

\section{Constância e inconstância: o acontecer na escola}

Uma concepção como a que aqui sustentamos, deve levar em consideração o acontecer da escola, o acontecer do aluno, como um todo do processo envolvido. A ideia de pensar a antropofagia como potencial pedagógico não só pede como exige a outra parte envolvida no processo. A antropofagia abre-se assim em uma dimensão de alteridade e de escuta para o outro, para que possa se fazer escola, se fazer filosofia, que não se queira catequese. "Absorver o outro e, nesse processo, alterar-se". (VIVEIROS DE CASTRO, 2013, p. 207). É essa alteração através da absorção de outrem que reside o sentido de toda antropofagia. Todo ensino e toda a aprendizagem pressupõem essa abertura para o outro, abertura essa, que de tão característica do antigo gentio brasileiro, assumiu formas no modo de ser do próprio aluno: esse inconstante por natureza. "A inconstância da alma selvagem, em seu momento de abertura, é a expressão de um modo de ser onde é a troca, não a identidade, o valor fundamental a ser afirmado". (2013, p. 206). A constância que se percebe na escola é única e exclusivamente constância da instituição e só ela não percebe a fluidez com que por ela passeia o seu aluno. O aluno é desde sempre um devorador, um antropófago, sempre receptivo. Receptividade com seus poréns: "receptividade (inconstante) ao discurso europeu..." (VIVEIROS DE CASTRO, 2013, p. 209). É essa receptividade inconstante, característica da alma "selvagem", tematizada por viveiros de Castro que nos chama atenção no trabalho em sala de aula. $O$ aluno nunca é uma constante. Ele é mutação e devir. Ao mesmo tempo em que se 
converte, no instante seguinte já esquece e passa a preocupar-se com outras práticas. Esse modus próprio do aluno, próprio da idade e também, por que não, da ontologia própria do brasileiro é o que o caracteriza e o distingue de modo tão fundamental quanto a outros povos. O aluno brasileiro não se deixa catequizar e isso, a nosso ver, por mais que dificulte em grande parte o trabalho em sala de aula é uma virtude a ser exaltada.

O professor, enquanto "condutor" dessas almas, não mais encarna o Jesuíta, cuja função era dar a conhecer ao gentio a palavra da salvação. Ao contrário, não seria aqui o professor de filosofia mais um mostrador de descaminhos? O professor também não se mostra, na maioria das vezes como também um desencaminhado? Nesse caso, uma pista de como pensar o professor enquanto tal poderia partir da concepção nietzschiana, que esboçaremos numa rápida citação de Ecce Homo, quando este relata a si mesmo enquanto professor: "Sempre fui capaz de superar o acaso - eu tenho de estar despreparado, para me tornar senhor de mim mesmo." (NIETZSCHE, 2010, p. 32). Esta citação traz à tona o essencial despreparo, o despreparo constitutivo da docência, que tantas vezes fugimos em sala de aula, em nossa busca pela constância, constância da escola e autoconstância. Mas se buscamos aqui uma prática filosófica apropriativa e, portanto, inconstante, que sentido faz colocarmo-nos como detentores de uma espécie de saber supremo, jesuítico? O professor, dentro da visão que aqui defendemos - e que a muitos pode parecer caótica - é também um antropófago e um inconstante, devora conceitos, rumina, vomita e os abandona, tão logo não Ihe apeteça mais. Dessa forma, podemos rapidamente esboçar um quase paralelismo entre os conceitos de antropofagia e os conceitos antropológicos de Viveiros de Castro: "[...] perspectivismo como um conceito da mesma família política e poética que a antropofagia de Oswald, isto é, como uma arma de combate contra a sujeição cultural da América latina, índios e não índios confundidos, aos paradigmas europeus e cristãos." (VIVEIROS DE CASTRO, 2013 p.129). Àqueles acostumados ao know-how eurocêntrico de sala de aula, essa pode parecer uma prática completamente absurda, até mesmo incoerente, mas como sugere o próprio Viveiros de Castro - e não nos valemos dessa fala senão 
apropriativamente - essa é a única forma de insubordinação, de insurgência latinoamericana no ensino médio. Tal como nos alerta Oswald, "nós sofremos duma terrível mentalidade colonial. Bom é o que nos é imposto." (ANDRADE, 1970, p.163) O que precisamos em filosofia não é de alunos que decorem o imperativo categórico, mas que de certa forma coloquem em prática o imperativo devoratório. Contra os tradicionais moldes da sujeição e da acomodação no ensino, vamos buscar o que é nosso.

\section{Aos 45 do segundo tempo: o tempo contra o ócio}

Desde sua origem, a filosofia é (quase sempre) compreendida como atividade puramente contemplativa, necessitando para tanto, do bom proveito do ócio. Oswald, no entanto, nos coloca outra questão, que para além da grega e do seu ócio contemplativo, com ares de sagrado, nos incomoda enquanto pensamos a escola e o ensino de filosofia nela inserido como em função de. Explicamo-nos: a noção de ócio para Oswald aparece explicitamente na descrição que este faz da guerra dos holandeses contra o Brasil, como a culminância das ideias da Reforma, representarão a ideia de negócio. O que mostra Oswald é a batalha do ócio contra o negócio. "Uma pequena excursão filológica pelas variações do vocábulo 'ócio' elucida o assunto. Assim, sacerdócio é ócio sagrado, como já dissemos. Negócio é a negação do ócio." (ANDRADE, 1970, p.159/60). Esse é o conflito que nos debatemos ao encarar o ensino de filosofia sob nossa perspectiva. Como ensinar com o tempo reduzido ao tempo do negócio? Como ensinar filosofia com os reduzidos 45 minutos semanais do ensino médio? E ainda assim, o que fazer com esses míseros 45 minutos, que existem apenas para serem "trabalhados"? O desafio do tempo do ócio contra o tempo medido, o tempo trabalhado, o tempo do negócio, do não-ócio. Esse é de fato, o maior problema com que nos debatemos ao afirmarmos tal proposta pedagógica: clamar pelo ócio para formar para o negócio. Eis um paradoxo que talvez jamais conseguiremos resolver. Esclarecedor é, no entanto, uma palavra que nos traz Raul Bopp, em um pequeno glossário antropofágico em que explicita uma disposição de humor, quiçá, disposição de caráter do brasileiro, que, para o nosso contexto é muito significativa: 
Mussangulá; revela uma posição de espírito que condensa problemas pessoais, numa acomodação surrealista. É um estado de aceitação, de instinto obscuro, subconsciente, mágico, pré-lógico. Renuncia compreender claramente as coisas. Espécie de preguiça filosófica, de moldura brasileira: estou de mussangulá! A palavra entrou para o idioma, significando uma defesa de espírito, que não quer se enquadrar em preceitos. Portanto, contra tudo o que é coerente, silogístico, geométrico, cartesiano (Bopp, 1977, p.48).

O ócio que buscamos, talvez seja essa espécie de Mussangulá, essa defesa espiritual e ao mesmo tempo apropriativa do que não faz parte da rotina do aluno. O aluno está constantemente de Mussangulá! E longe de quebrarmos com essa disposição tão fundamental, gostaríamos de explorá-la ao máximo. A filosofia, retomando o jargão antropofágico, apresenta-se assim não como ato do mero pensar, mas antes, de mastigar, engolir e digerir. Tão importante quanto, é necessário que a filosofia seja indigesta. Do interior dessa pedagogia da devoração, nos opomos a uma filosofia "mastigada", pronta. O potencial de um ensino de filosofia antropofágico envolve o ato voluntário de "mastigação" por parte do aluno, a tão falada e sonhada autonomia. Como é possível que o aluno filosofe se Ihes damos tudo pronto? Como é possível aprender a comer, sem antes mastigar? Nessa busca ideal de autonomia e autossuficiência do aluno, voltamos com o tema da devoração simbólica que envolvia os ritos antropofágicos:

A fim de melhor compreender o sentido totêmico, de comer o seu semelhante, isto é, fazer, em disposições mágicas, uma absorção de forças em comunhão incruenta. $O$ índio, antes do arado, era feliz na sua dignidade humana. Mas chegaram os pregoeiros da catequese. Mandaram perguntar, em Roma, 'se o gentio era gente?' (Bopp, 1977, p.41).

Para o aluno do ensino médio - que nos perguntamos em Roma, ou no MEC se já é gente - tanto importa se lhe apresente o sistema de pensamento A ou B. Em uma palavra, não Ihe interessa a tradição. Nesse sentido, a antropofagia, não se apresenta como um sistema de pensamento, mas como base metodológica de "trabalho", onde o sentido apropriativo da filosofia torna-se manifesto para que se torne frutífero o ensino em sala de aula. A antropofagia aparece assim como o modo de apreender tais sistemas, seja ele A ou B, apresentando-o de maneira instigante ao aluno que se apropriará de dito conteúdo. 
A título de conclusão, podemos enfim, tentar esboçar algumas respostas às questões levantadas no início deste trabalho, a saber, a ligação entre os conceitos de antropofagia, apropriação e autonomia. Durante todo o texto, jogamos implicitamente com o conceito de antropofagia como sinônimo de apropriação de conceitos. Antropofagia e devoração aqui foram usadas como metáforas, mas metáforas vivas de uma tradição filosófica ainda por desenvolverse. Nesse sentido, a noção de antropofagia como apropriação nos leva diretamente a uma concepção de autonomia por parte do aluno. O aluno mais do que engolir conteúdos, deve apropriar-se antropofagicamente destes. No que toca a outra questão - em que sentido Oswald de Andrade pode ser visto como educador? A resposta já está inclusa na primeira. Na medida em que pensamos a antropofagia oswaldiana como apropriação e exercício da autonomia, Oswald teria uma proposta pedagógica revolucionária, se comparada com os modos de se pensar filosofia e seu ensino no Brasil. Sua proposta pedagógica é justamente essa: Devorar, mas devorar apenas o que nos interessa. Nas palavras de Cabrera:

\begin{abstract}
Quando leio Heidegger, por exemplo, como devo ler para ser um bom antropófago e não meramente um comentador canibal e faminto? Em primeiro lugar, não deveria lê-lo bem, ou seja, de maneira confiável [...] deveríamos comer Heidegger por pedaços, tirar os mais gostosos de acordo com nossos próprios projetos e expectativas sem qualquer compromisso de ter de acompanhá-lo até o fim em seu próprio percurso assimilativo: tenho meu percurso senhor Heidegger, e posso abandonar o senhor quando quiser, não confie em mim (CABRERA, 2010, p.165).
\end{abstract}

Agora acreditamos estar em condições de expor aquilo que chamamos de os sentidos e limites da antropofagia enquanto potencial pedagógico. Obviamente, não visamos expor aqui a antropofagia com pretensões messiânicas para o ensino de filosofia no ensino médio. O objetivo era justamente que se colocasse em prática o exercício de apropriação proposto na obra oswaldiana e que o pudéssemos pensá-lo em seu potencial pedagógico, em sua aplicação - se nos for lícito usar essa palavra - no ensino médio. Nesse caso, ficam nítidos os pontos fracos da proposta: ela parte da concepção de que o aluno está sempre aberto, sempre faminto; coisas que a prática em sala de aula nos mostra no mais das vezes o contrário. Em suma, os limites de uma prática filosófica 
antropofágica se mostram quando não levamos em conta o contexto em que a mesma será inserida. Pensamos uma pedagogia antropofágica, por outro lado, como hipótese plausível para pensar o ensino de filosofia que não se queira meramente reprodutivo e repetitivo, mas sim, criador, emancipador.

\section{Referências Bibliográficas}

ANDRADE, Oswald de. Do Pau-Brasil à Antropofagia e às Utopias. Obras Completas Vol. VI. Rio de Janeiro: Civilização Brasileira, 1978.

ASTRADA, Carlos A filosofia latino-americana como expoente de uma cultura autônoma. Sopro 40 Novembro/2010. Disponível em: <http:culturaebarbarie.org/sopro/astrada.html>.

BRASIL, Ministério da educação e cultura. Orientações Curriculares - Conhecimentos de Filosofia. Distrito Federal, 2006.

BRASIL, BRASÍLIA. Lei de Diretrizes e Bases da Educação Nacional (LDB),1996.

CABRERA, Julio. Diário de Um Filósofo no Brasil. ljui: Editora Unijuí, 2010.

CEPPAS, Filipe Ensino de Filosofia, antropologia e antropofagia. Anais do VIII Seminário Filosofia na Escola, UFSM, 2013.

CEPPAS, Filipe. Anotações Sobre a História do Ensino de Filosofia no Brasil. In: Cornelli ,G., Carvalho, M., Danelon, M. (Coord.):Coleção Explorando o Ensino: Filosofia, V14, Brasília: Ministério da Educação, 2010.

CERLETTI, Alejandro. O ensino de filosofia: como problema filosófico. Tradução de Ingrid Müller Xavier. Autêntica, Belo Horizonte. 2009.

BOPP, Raul. Vida e Morte da Antropofagia. Rio de Janeiro, Civilização Brasileira, 1977.

BOPP, Raul. Movimentos Modernistas no Brasil 1922- 1928. Rio de Janeiro, Livraria São José, 1966.

GALO, Sílvio. Metodologia do ensino de filosofia : Uma didática para o ensino médio. Papirus, São Paulo. 2012.

JÉLVEZ, Julio Alejandro Quezada. A pesquisa como princípio pedagógico no Ensino Médio. Reestruturação do ensino médio : pressupostos teóricos e desafios da prática / organização José Clóvis de Azevedo, Jonas Tarcísio Reis. - 1. ed. - São Paulo : Fundação Santillana, 2013.

NIETZSCHE, Friedrich. Ecce Homo. Tradução de Marcelo Backes. Porto Alegre: L\&PM Editores, 2010.

NUNES, Benedito. Antropofagia ao alcance de todos. Obras Completas de Oswald de Andrade. Vol. VI. Rio de Janeiro: Civilização Brasileira, 1978.

PORCHAT, Oswaldo. Discurso aos Estudantes Sobre a Pesquisa em Filosofia, In: Souza, José Cristódomo de: A Filosofia entre nós, ljuí: Editora Unijuí, 2006. 
RIBEIRO, Darcy. Encontros: Eduardo Viveiros de Castro. Apresentação Guilherme Zarovs. Rio de Janeiro : Beco do Azougue, 2007.

VIVEIROS DE CASTRO, Eduardo. A Inconstância da Alma Selvagem e outros ensaios de antropologia. São Paulo: Cosac Naify, 2013. 